\title{
Incorrect Labeling and/or Instructions for Use
}

National Cancer Institute

\section{Source}

National Cancer Institute. Incorrect Labeling and/or Instructions for Use. NCI Thesaurus. Code C92136.

Missing, incorrect, or inappropriate information on the labels e.g. mislabeled contents or device labeling characteristics or package contents 